\title{
AtCDC5 regulates the $\mathbf{G} 2$ to $M$ transition of the cell cycle and is critical for the function of Arabidopsis shoot apical meristem
}

\author{
Zhiqiang Lin ${ }^{1}$, Kangquan Yin ${ }^{1}$, Danling Zhu ${ }^{1}$, Zhangliang Chen ${ }^{1,2}$, Hongya Gu ${ }^{1,2}$, Li-Jia Qu ${ }^{1,2}$ \\ ${ }^{I}$ National Laboratory for Protein Engineering and Plant Genetic Engineering, Peking-Yale Joint Research Center for Plant Molecular \\ Genetics and AgroBiotechnology, College of Life Sciences, Peking University, Beijing 100871, China; ${ }^{2}$ The National Plant Gene \\ Research Center (Beijing), Beijing 100101, China
}

As a cell cycle regulator, the Myb-related CDC5 protein was reported to be essential for the G2 phase of the cell cycle in yeast and animals, but little is known about its function in plants. Here we report the functional characterization of the CDC5 gene in Arabidopsis thaliana. Arabidopsis CDC5 (AtCDC5) is mainly expressed in tissues with high cell division activity, and is expressed throughout the entire process of embryo formation. The AtCDC5 loss-of-function mutant is embryonic lethal. In order to investigate the function of AtCDC5 in vivo, we generated AtCDC5-RNAi plants in which the expression of $A t C D C 5$ was reduced by RNA interference. We found that the $\mathrm{G} 2$ to $\mathrm{M}(\mathrm{G} 2 / \mathrm{M})$ phase transition was affected in the AtCDC5-RNAi plants, and that endoreduplication was increased. Additionally, the maintenance of shoot apical meristem (SAM) function was disturbed in the AtCDC5-RNAi plants, in which both the WUSCHEL (WUS)CLAVATA (CLV) and the SHOOT MERISTEMLESS (STM) pathways were impaired. In situ hybridization analysis showed that the expression of $S T M$ was greatly reduced in the shoot apical cells of the AtCDC5-RNAi plants. Moreover, cyclinB1 or Histone 4 was found to be expressed in some of these cells when the transcript of STM was undetectable. These results suggest that $A t C D C 5$ is essential for the $\mathrm{G} 2 / \mathrm{M}$ phase transition and may regulate the function of SAM by controlling the expression of STM and WUS.

Keywords: AtCDC5, G2/M phase transition, shoot apical meristems, WUS, STM

Cell Research (2007) 17:815-828. doi: 10.1038/cr.2007.71; published online 4 September 2007

\section{Introduction}

In multicellular organisms, cell division plays a crucial role in development. The cell division cycle is well studied in single-cell systems, and molecular mechanisms that ensure the fidelity of DNA replication have been defined. The $\mathrm{G} 2$ to $\mathrm{M}(\mathrm{G} 2 / \mathrm{M})$ phase transition is an important checkpoint in the regulation of the cell cycle, and is the point at which the fidelity of the replicated DNA is verified. Cells with defects in $\mathrm{G} 2 / \mathrm{M}$ phase transition can enter

\footnotetext{
Correspondence: Li-Jia Qu

Fax: +86-10-6275-3339

E-mail: qulj@pku.edu.cn

Received 5 June 2007; revised 19 June 2007; accepted 19 June 2007; published online 4 September 2007
}

the endoreduplication mode and undergo one or more rounds of DNA replication without intervening mitosis $[1,2]$. For instance, in transgenic Arabidopsis thaliana plants that have reduced activity of CDKB1;1, a regulator of G2/M transition, stomatal cells become arrested at $\mathrm{G} 2 / \mathrm{M}$ and show enhanced endoreduplication [3]. When the dominant-negative allele of $C D K B 1 ; 1$ was overexpressed in E2Fa-DPa-overproducing plants, the endoreduplication phenotype of these plants was stronger, but the extra mitotic activity caused by E2Fa-DPa was suppressed [4]. In another case misexpression of ICK/KRP1, a possible inhibitor of CDKA;1, in Arabidopsis trichomes could block G1/S and G2/M transitions in a concentration-dependent manner [5]. A high concentration of ICK/KRP1 can inhibit the G1/S transition and suppress endoreduplication [6], whereas low-level misexpression blocks the G2/M transition and 
induces endoreduplication [5].

In plants, shoot apical meristem (SAM) cells play critical roles in many aspects of development and the cell cycle of SAM cells is highly regulated [7]. Two major signaling pathways that are involved in establishing and maintaining SAM cells have been characterized. These are the WUSCHEL (WUS)-CLAVATA (CLV) pathway and the SHOOT MERISTEMLESS (STM) pathway [8-12]. WUS encodes a homeobox transcription factor that is necessary for the expression of $C L V 3$. The protein encoded by $C L V 3$ binds to its receptor CLV1 to trigger downstream signals, and this in turn represses the expression of $W U S$. Thus, a feedback loop is set between $W U S$ and $C L V 3[13,14]$. In the STM pathway, STM is a KNOTTED1-like homeobox (KNOX) gene [12], and its known downstream genes include $A S 1$ and $A S 2[15,16]$, which encode an Myb transcription factor and a leucine zipper transcription factor, respectively. Genetic studies have demonstrated that STM keeps SAM cells in an undifferentiated state by repressing the expression of $A S 1$ and $A S 2$. These two genes can promote the formation of primordia by suppressing $K N O X$ genes, including $K N A T 1$, KNAT2 and KNAT6 $[15,17,18]$.

Despite extensive knowledge about the genes that regulate the cell cycle and those that are involved in SAM functions, the link between these two categories of genes remains unclear [19]. Myb-related CDC5 proteins are functionally and structurally conserved across the eukaryotic kingdoms [20]. The CDC5 gene was first isolated from Schizosaccharomyces pombe and has been demonstrated to function at the $\mathrm{G} 2 / \mathrm{M}$ phase transition [21]. In yeast, mammals and Arabidopsis, the CDC5 proteins can bind to specific DNA sequences in vitro; therefore, CDC5 might serve as a transcription factor to regulate mitotic entry [21-25]. The CDC5 protein has also been proved to be a crucial component of the spliceosome, and it is essential for mRNA splicing in fission yeast and humans [26-30]. Further genetic studies in yeast show that the loss of CDC5/ Ceflp function results in cell cycle defects by influencing the splicing of TUB 1 mRNA [31,32]. The CDC5 homolog in Arabidopsis, AtCDC5, has been reported to be able to rescue the phenotype of the temperature-sensitive $c d c 5$ mutant in $S$. pombe, and was found to bind DNA in vitro [24]. Recent studies demonstrate that AtCDC5 is localized in the nucleus and that the $\mathrm{C}$-terminus of this protein has transactivation activity in yeast. Moreover, silencing of this gene in Arabidopsis results in accelerated cell death [33].

In this study, we report the functional characterization of AtCDC5 in Arabidopsis to investigate its roles in plant development. We found that $A t C D C 5$ is mainly expressed in proliferating tissues of all phases, and the AtCDC5 lossof-function mutant is lethal at the zygote stage. In AtCDC5RNAi plants, the $\mathrm{G} 2 / \mathrm{M}$ phase transition is severely affected,
SAM function is impaired, and the STM and WUS-CLV signaling pathways are suppressed. The results suggest that $A t C D C 5$ is essential for the G2/M phase transition in Arabidopsis, and is critical for SAM function.

\section{Material and Methods}

\section{Generating AtCDC5-RNAi transgenic plants}

To create an RNAi construct, a 365-bp fragment (637-1001) of AtCDC 5 cDNA was amplified by RT-PCR [33]. It was then cloned, in the sense and antisense orientations, into the pQVF binary vector. These two fragments were separated by an 800-bp fragment of the $\beta$-glucuronidase (GUS) gene (Figure 1A) [34]. The positive clones were sequence confirmed. This plasmid, designated pQVF-AtCDC5i, was introduced into Agrobacterium tumefaciens (GV3101). Arabidopsis plants (ecotype Columbia-0) were transformed using the floral-dip method [35]. Transformed plants were screened against kanamycin and grown in the greenhouse under long-day conditions ( $16 \mathrm{~h}$ of light with $8 \mathrm{~h}$ of dark) after being transferred into soil. The transgenic plants were verified by PCR.

\section{Northern blot and qRT-PCR}

To carry out northern blot analysis of STM, CLV1 or AtCDC5 expression, a part of the coding region was amplified by RT-PCR and used as a template for the synthesis of $\mathrm{P}^{35}$-labeled random probes. RNA extraction and northern blot analysis were carried out as previously reported [36, 37]. cDNA synthesis and real-time quantitative RT-PCR were performed on a DNA Engine Opticon system (MJ Research, Cambridge, MA, USA) according to the protocols that have previously been described [38]. The primers used for the northern blot and real-time qRT-PCR analyses are:

AtCDC5 5'-aag geg gag gaa gaa gca-3', 5'-gaa get tcc atg get atg gc-3';

$C D K B 1 ; 15^{\prime}$-ctt cat atc ttc agg ttg c-3', 5'-tca gaa ctg aga ctt gtc aa-3';

cyclinB1 $5^{\prime}$-atg atg act tct cgt tcg att gtt-3', 5'-atc ctc cac aag aag cgt ggg att-3';

$K R P 15^{\prime}$-atg gtg aga aaa tat aga aaa g-3', 5' - ccc gct aca aca aca atc taa cg-3';

STM 5'-atg gag agt ggt tcc aac agc-3', 5'-tca aag cat ggt gga gga gat gt-3';

CLV1 5'-aag gac acg gtc tcc acg act g-3', 5'-acc ggt gta get gtt gta gt- $3^{\prime}$;

WUS 5'-gtc tat gga tct atg gaa c-3', 5'-cta gtt cag acg tag ctc aag aga-3';

$A S 15^{\prime}$-gaa ccg tga cge caa gtc ttg t-3', 5'-ctc gtc aat agg ctc aac tct c-3';

KNAT1 5'-acc gag aat tge ttc cga tct g-3', 5'-gec gtg ceg ccg taa ttc tat c-3';

Ubiquitin-10 5'-tcc gga tca gca gag get ta-3', 5'-tca gaa ctc tcc acc tca ag- $3^{\prime}$.

\section{Electron microscopy}

For scanning electron microscopy, shoot apices were fixed in FAA ( $50 \%$ ethanol, $5 \%$ acetic acid and $3.7 \%$ formaldehyde), vacuumed and dehydrated in a series of ethanol. The $100 \%$ ethanol was then replaced by isoamyl acetate. The samples were dried with $\mathrm{CO}_{2}$ at critical point, sputter coated with gold and observed with an S-800 
scanning electron microscope (Hitachi, Tokyo) at an accelerating voltage of $30 \mathrm{kV}$.

\section{Flow cytometric analysis}

Nuclei from seedlings and rosette leaves were prepared as already described [39]. To eliminate the RNA, the nucleus was digested with RNase (with a final concentration of $4 \mu \mathrm{g} / \mathrm{ml}$ ) at $37{ }^{\circ} \mathrm{C}$ for $20 \mathrm{~min}$, and then $2 \mu \mathrm{l}$ PI $(5 \mathrm{mg} / \mathrm{ml})$ was added. The samples were subjected to flow cytometric analyses with a FACSCalibur flow cytometer (Becton, Dickinson and Company, USA), equipped with an argon ion laser at $488 \mathrm{~nm}$, and the fluorescence was examined at $580 \mathrm{~nm}$. Histograms were produced using the CellQuest software (Becton, Dickinson and Company, USA). The number of nuclei present at each peak of the histogram (2C, 4C, 8C and 16C) was analyzed by measuring the peak area.

\section{Histological and whole-mount tissue studies}

In order to monitor embryogenesis, developing seeds from wild type and atcdc5-1 (+/-) plants were removed from the siliques and cleared as has been previously described [40] and then examined using Nomarski optics with an optical microscope (Olympus BX51, Tokyo, Japan).

To carry out histological analysis, seedlings and inflorescences were fixed in FAA for $20 \mathrm{~h}$ at $4{ }^{\circ} \mathrm{C}$, dehydrated in an ethanol/xylene series and embedded in paraffin. Embedded tissues were sectioned to an 8 - $\mu \mathrm{m}$ thickness, placed onto glass slides, dried and stained with safranine and fast green.

GUS staining [41] was carried out as previously described.

\section{In situ hybridization}

In situ hybridizations were carried out as previously described [37]. The templates used for synthesizing antisense transcripts were all cloned into pBS and sequence was conformed. The primers used for amplifying the templates are AtCDC5 $5^{\prime}$-gcg ctt acg agc tct caa gt- $3^{\prime}, 5^{\prime}$-cca tct ctt ctt gec tct tc-3'; cyclinB1 $5^{\prime}$-atg atg act tct cgt tcg att gtt-3'; $5^{\prime}$-atc ctc cac aag aag cgt ggg att-3'; STM $5^{\prime}$-gec gca gec get gec gca tct a-3'; 5'-tca aag cat ggt gga gga gat gt- $3^{\prime} ;$ Histone $45^{\prime}$-atg tcg gg tcg tgg aaa ggg agg- $3^{\prime} ; 5^{\prime}$-ctt cet cet age gtg ctc ggt gt- $3^{\prime}$.

\section{Results}

\section{AtCDC5 loss-of-function mutant is lethal at the zygote stage}

To investigate the function of AtCDC5, we obtained an AtCDC5 loss-of-function mutant, GABI-KAT line 278B09 (hereafter designated as atcdc5-1), in which two T-DNA insertions were found in the fourth exon of AtCDC5 (Figure 1A). Segregation was analyzed using the T3 population. Out of 191 T3 plants, 122 were heterozygous and no homozygous mutants were found. This suggests that atcdc5-1 is a recessive, lethal mutant of AtCDC5. Phenotypically, heterozygous atcdc5-1 (+/-) mutants were largely identical to wild-type plants. However, when the siliques were examined about one-quarter of the seeds had been aborted (Figure 1B), indicating that seed development for the homozygous atcdc5-1 (-/-) mutants terminates prematurely. We examined embryonic development in the ovules of

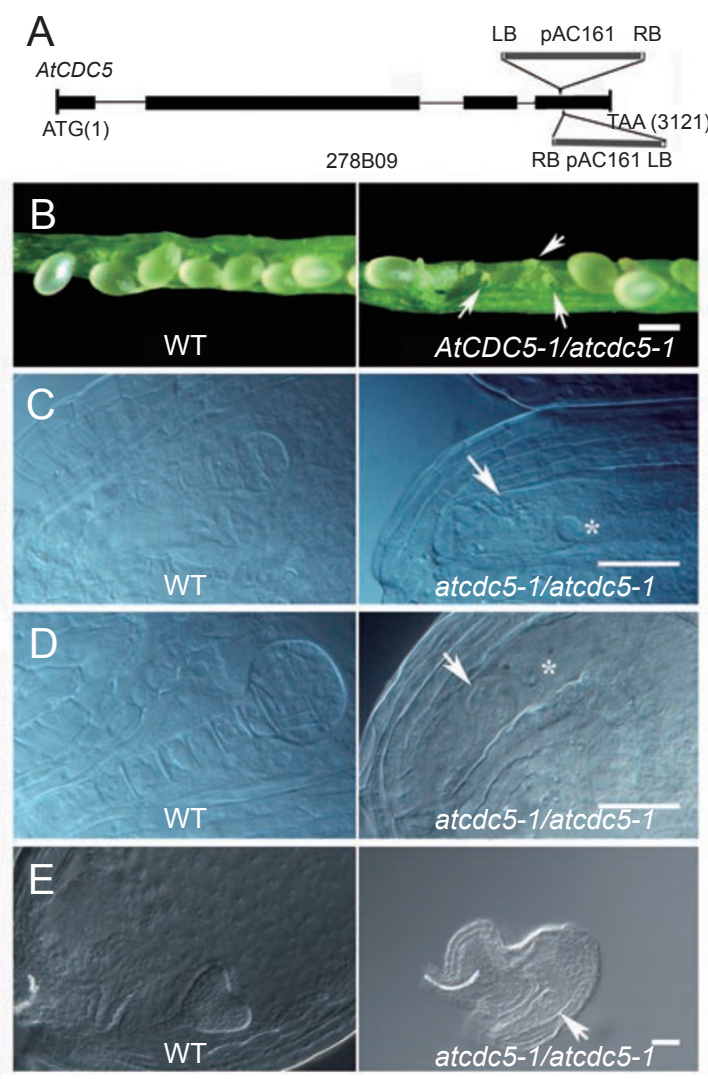

Figure 1 Characterization of the T-DNA insertion mutant atcdc51. (A) Schematic representation of the T-DNA insertion sites in atcdc5-1. Exons and introns are represented by black boxes and lines, respectively. Gray boxes represent T-DNA inserts. (B) Siliques of wild type (WT) and atcdc5-1 (+/-) plants. Aborted seeds are indicated by arrows. (C) Wild type and atcdc5-1 (-/-) embryos at 36 hap. The wild-type embryo is at the 8-cell stage; however, the mutant embryo (indicated by an arrow) is arrested as a zygote in a seed containing a single endosperm nucleus (indicated by an asterisk). (D) Wild type and atcdc5-1 (-/-) embryos at 48 hap. The wild-type embryo is at the globular stage. The mutant embryo (indicated by an arrow) remains at the zygote stage but is enlarged. There is only a single endosperm nucleus at this time (indicated by an asterisk). (E) Wild type and atcdc5-1 (-/-) embryos at 72 hap. Note that the atcdc5 (-/-) embryo (indicated by an arrow) is still at the zygote stage, and no endosperm nucleus can be seen. Bars: $(\mathbf{B})=500 \mu \mathrm{m} ;(\mathbf{C}-\mathbf{E})=25 \mu \mathrm{m}$.

atcdc5-1 (+/-) plants. At $36 \mathrm{~h}$ after pollination (hap), wildtype embryos were at the 8-cell stage, but atcdc5-1 (-/-) embryos were at the zygote stage (Figure 1C). At 48 hap, when the wild-type embryos were at the globular stage, the atcdc5-1 (-/-) embryos, still at the zygote stage, were enlarged abnormally (Figure 1D). At 72 hap, the wild-type embryos were at the heart stage; however, the seeds containing atcdc5-1 (-/-) embryos were aborted, and remains of a large cell, probably the defective zygote, were found 
inside (Figure 1E). Besides the defective zygote, the endosperm nucleus failed to divide in these atcdc5-1 (-/-) seeds (Figure 1C and 1D, indicated by asterisks). These results suggest that $A t C D C 5$ is essential for the cell division of the embryo and endosperm, and that $A t C D C 5$ loss-of-function results in lethality at the zygote stage.

\section{AtCDC5 is predominantly expressed in proliferating cells}

It has been reported that $A t C D C 5$ encodes a putative cell cycle regulator that is mainly expressed in proliferating tissues [24]. To further clarify the connection between the AtCDC5 expression pattern and development, in situ hybridization was conducted using wild-type embryos and flowers. At the one-cell stage, AtCDC5 transcripts could be detected in both the embryonic cells and the endosperm nucleus (Figure 2A, indicated by arrowhead). At the 4-cell stage and globular stage, AtCDC5 was expressed in all the embryonic and endosperm cells (Figure $2 \mathrm{~B}$ and $2 \mathrm{C}$ ). At the heart stage and torpedo stage, $A t C D C 5$ was expressed
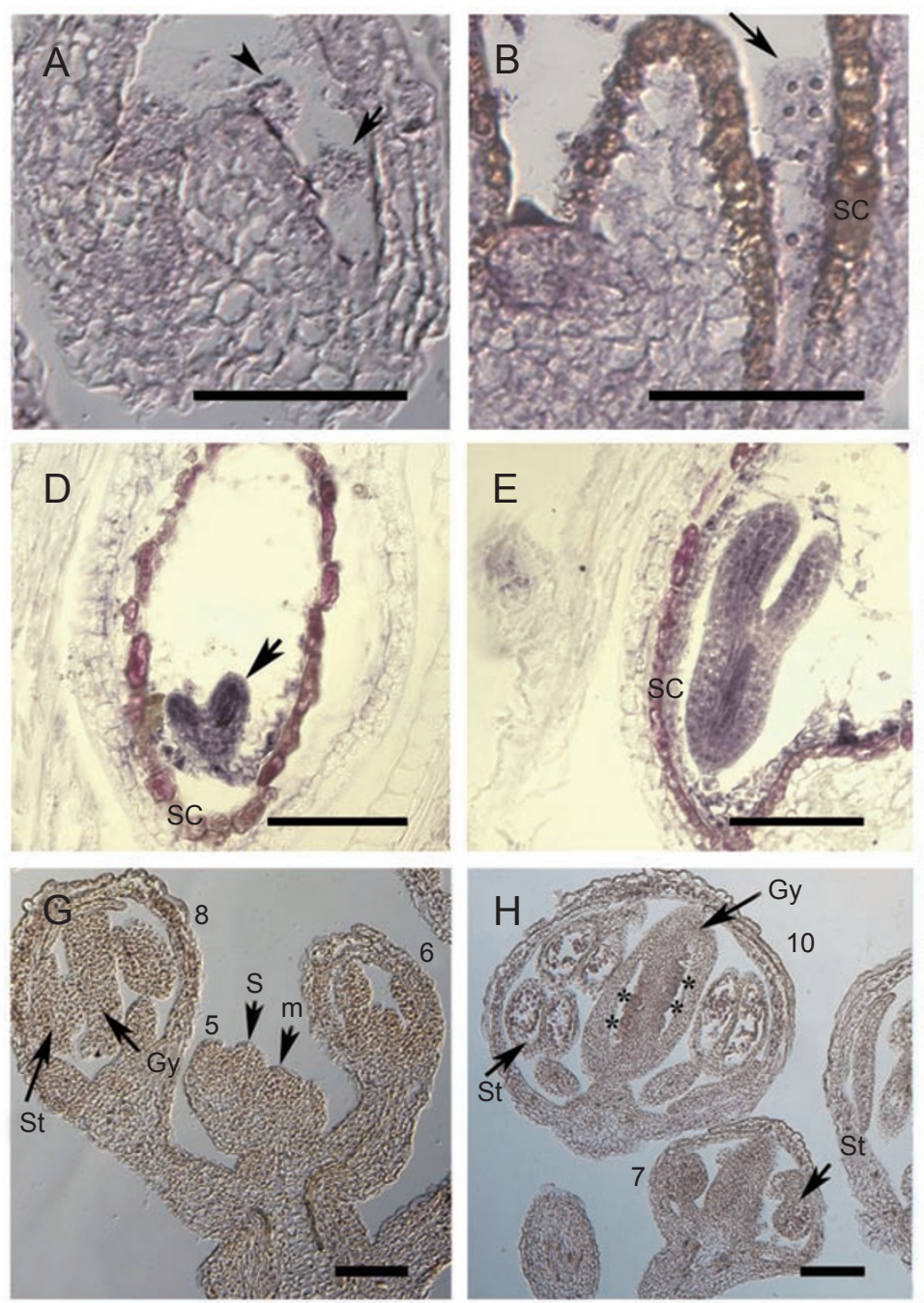
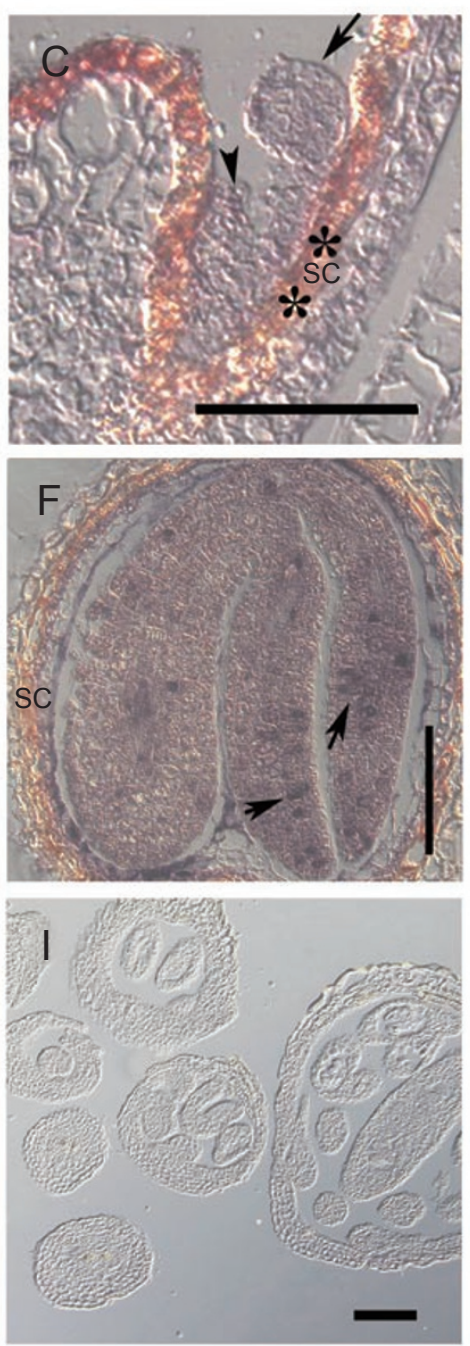

Figure 2 Expression pattern of $A t C D C 5$. Labeled antisense transcripts were hybridized with sections of wild-type tissue. (A) One-cell embryo. (B) 8-cell embryo. SC: seed coat. (C) Globular-stage embryo. (D) Heart-stage embryo. AtCDC5 is expressed throughout, but particularly abundantly in the cotyledon primordia (arrow). (E) Torpedo-stage embryo. AtCDC5 is highly expressed in cotyledon primordia and radicle primordia cells. (F) Mature embryo. Expression of AtCDC5 is enriched in some cotyledon cells (arrows). (G) Inflorescence. AtCDC5 is highly expressed in inflorescence meristem (m) and developing flowers. The development stages of the flowers are indicated by numbers. S: Sepal primordia; St: young stamen; Gy: gynoecium. (H) Flower at stage 7 and stage 10. Ovule primordia are indicated by asterisks. (I) Sense control. No signal can be detected. Bars $=100 \mu \mathrm{m}$. 
throughout the embryo, but it was more abundant in the cotyledon and radicle primordia (Figure 2D and 2E). The transcript was detected throughout the entire mature embryo and it was particularly enriched in some cotyledon cells (Figure 2F, indicated by arrows). In the inflorescences, the $A t C D C 5$ transcript was more abundant in inflorescence meristems $(\mathrm{m}$ ) and developing flowers (Figure $2 \mathrm{G}$ and $2 \mathrm{H}$ ). In flowers at different developmental stages, $A t C D C 5$ was especially enriched in those tissues containing rapidly proliferating cells, such as the primordia of sepals (Figure 2G,

A

nos terminator

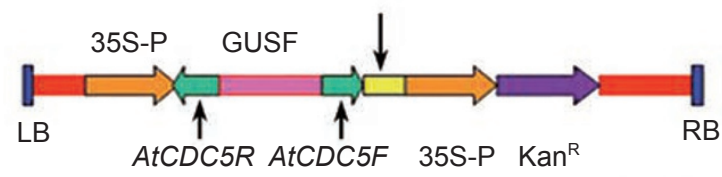

\section{$\overline{500 \mathrm{bp}}$}
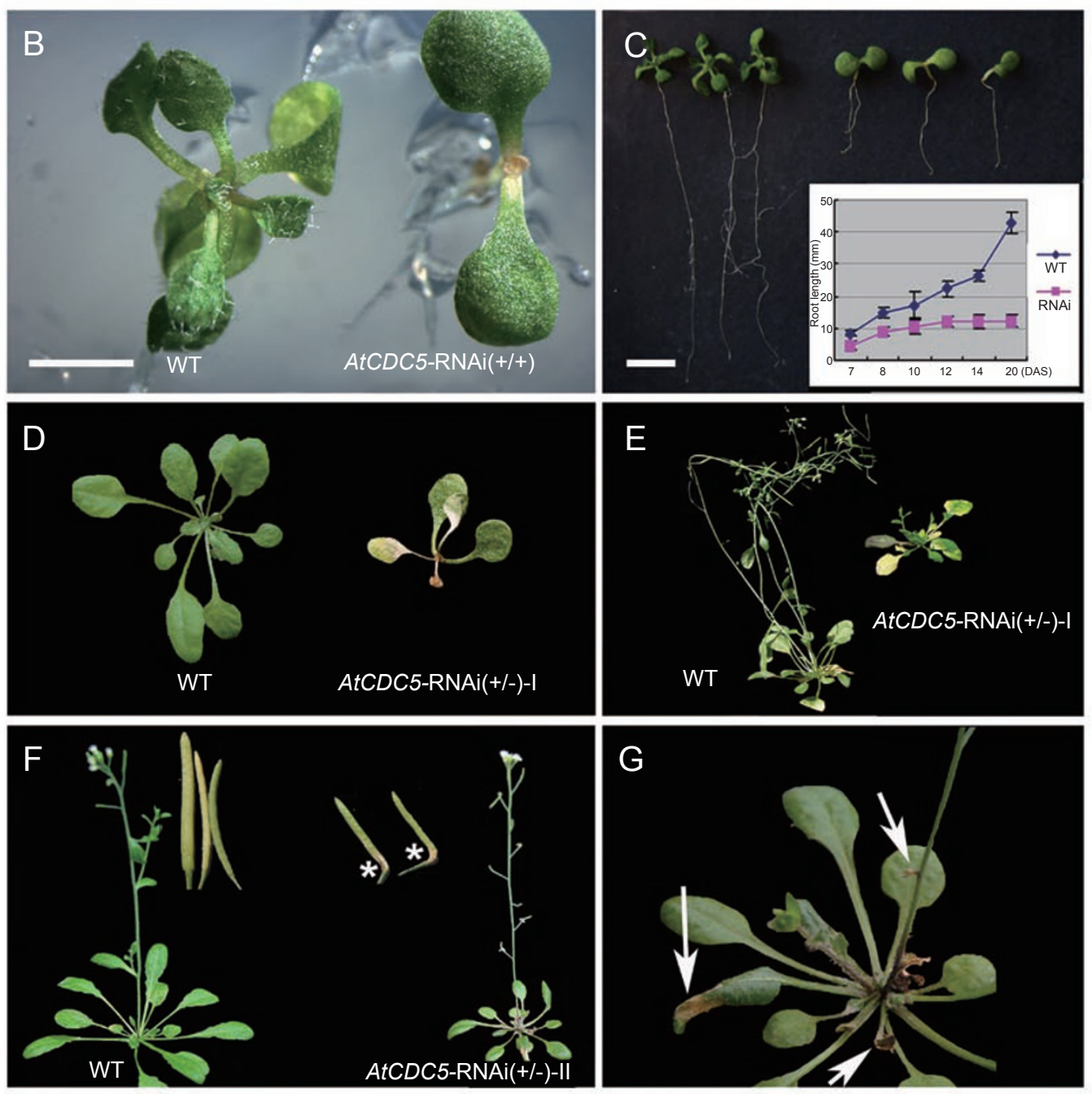

Figure 3 Phenotype of AtCDC5-RNAi plants. (A) A schematic representation of the AtCDC5-RNAi construct. Green boxes indicate the AtCDC5 fragments. (B) Phenotypes of 12-day-old WT and AtCDC5-RNAi (+/+) plants. Bar $=4$ mm. (C) Kinematic analysis of the root length of WT and $A t C D C 5-\mathrm{RNAi}(+/+)$ plants. Bar $=8 \mathrm{~mm}$. (D) Phenotypes of 35-day-old WT and AtCDC5-RNAi (+/-)-I plants. (E) Phenotypes of 60-day-old WT and AtCDC5-RNAi (+/-)-I plants. (F) Phenotypes of 40-day-old WT and AtCDC5-RNAi (+/-)-II plants. (G) Basal part of the AtCDC5-RNAi (+/-)-II plant shown in (F). Lesions are indicated by arrows. 
stage 5), young stamens and gynoeciums (Figure $2 \mathrm{G}$ and $2 \mathrm{H}$, stages 6-8), and ovule primordia (Figure $2 \mathrm{H}$, stage 10 , indicated by asterisks). No signal was detected in the negative control, which was hybridized with the sense probe (Figure 2I). Therefore, these results suggest that AtCDC5 is mainly expressed and enriched in proliferating cells.

\section{AtCDC5-RNAi plants display pleiotropic phenotypes}

Since homozygous loss-of-function plants are embryonic lethal, we adopted the RNAi strategy to investigate AtCDC5 function in post-embryonic development (Figure $3 \mathrm{~A}$ ). We generated 35 transgenic lines, of which three lines appeared to be wild type, whereas 32 partially or completely lacked the SAM. Out of the 32 RNAi mutants, only eight were fertile. Genetic segregation analysis determined that four out of the eight lines contained a single copy of the RNAi construct (Supplementary information, Table S1).

Phenotypic and co-segregation analysis showed that homozygous AtCDC5-RNAi plants (designated AtCDC5RNAi $(+/+)$ hereafter) had severe phenotypes (Supplementary information, Table S1). Death occurred at the cotyledon stage before mature true leaves emerged (Figure 3B), and their root growth was severely inhibited (Figure $3 \mathrm{C}$ ). However, heterozygous $A t C D C 5$-RNAi plants (designated $A t C D C 5$ - RNAi (+/-) hereafter) could generate true leaves, although at a slower pace, and showed pleiotropic phenotypes. Among the T3 generation of AtCDC5-RNAi $(+/-)$ plants, about $13 \%$ died with only four or fewer true leaves (Figure 3D). Approximately 39\% showed retarded, slow growth with abnormal rosette phyllotaxy and lacked primary inflorescence shoots (Figure 3E). The remaining $48 \%$ did not have obvious growth defects, but had a dwarf phenotype (Figure 3F), and paler lesions were found on young rosette leaves (Figure 3G) and siliques (Figure 3F). We divided AtCDC5-RNAi (+/) plants into two classes. The class I plants could not generate primary inflorescences, while the class II plants could. Supplementary information, Table S2 summarizes the phenotypes of the T3 generation of AtCDC5-RNAi (+/-) plants.

\section{Phenotypic severity in AtCDC5-RNAi plants corresponds to AtCDC5 expression level}

Northern blot analyses were conducted to investigate
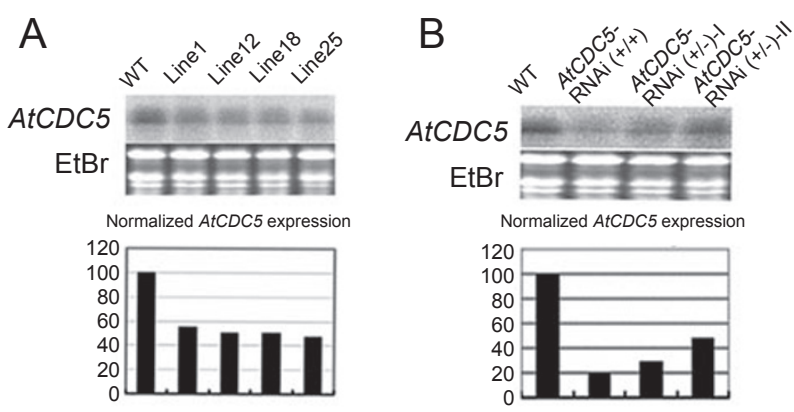

Figure 4 Dosage effect of $A t C D C 5$ on the phenotype of $A t C D C 5$ RNAi plants. (A) Northern blot analysis of $A t C D C 5$ in WT and $A t C D C 5$-RNAi plants. Four independent lines with single insertions are shown. (B) RNA gel blot analysis of $A t C D C 5$ in WT, $A t C D C 5$-RNAi (+/+), AtCDC5-RNAi (+/-)-I and AtCDC5-RNAi $(+/-)-$ II plants.

whether $A t C D C 5$ was silenced in the $A t C D C 5$-RNAi plants. The results showed that expression of $A t C D C 5$ was reduced in four independent $A t C D C 5$-RNAi (+/-)-II lines (Figure 4A), and in AtCDC5-RNAi (+/+), AtCDC5-RNAi (+/-)-I and $A t C D C 5$-RNAi (+/-)-II plants (Figure 4B). The expression levels of $A t C D C 5$ in the most severe $A t C D C 5$-RNAi $(+/+)$ plants, in the moderately severe $A t C D C 5$-RNAi(+/-)I plants and in the least severe $A t C D C 5$-RNAi (+/-)-II plants were about $20 \%, 35 \%$ and $50 \%$ of the wild-type level, in corresponding order. This shows a positive correlation between the reduction of $A t C D C 5$ expression level and the severity of the phenotypes (Figure 4B). The expression of $R A N 1$, which had 18 identical nucleotides to the RNAi fragment of $A t C D C 5$, was not affected (data not shown), thus excluding the possibility of nonspecific RNA silencing. Therefore, the variation of the phenotypes observed among the AtCDC5-RNAi lines likely reflects dosage-dependent defects that are due to loss of $A t C D C 5$ function.

\section{G2/M phase transition is severely affected in AtCDC5- RNAi plants}

In order to investigate whether AtCDC5 plays a similar role in the $\mathrm{G} 2 / \mathrm{M}$ phase transition to the $\mathrm{CDC} 5$ proteins in

Figure 5 Cell cycle analysis of AtCDC5-RNAi plants. (A to D) Kinetic analysis of ploidy level distribution in wild type (left) and AtCDC5-RNAi (+/+) (right) plants as measured by flow cytometry: (A) 7 DAS, (B) 8 DAS, (C) 10 DAS and (D) 11 DAS. Histograms represent average data from three independent measurements. (E) SEM image of adaxial epidermal cells of the fifth leaves at 5 weeks after sowing. One cell is outlined in red in each plant. Bars $=100 \mu \mathrm{m}$. The histogram represents the average size of 100 independent cells. (F) Expression analysis of KRP1, cyclinB1 and CDKB1;1. The level of KRP1, cyclinB1 and CDKB1;1 was normalized to that of Ubiqutin-10 mRNA and the relative mRNA level was calculated in reference to the WT level. Experiments were repeated three times and the standard deviation (SD) is shown. 

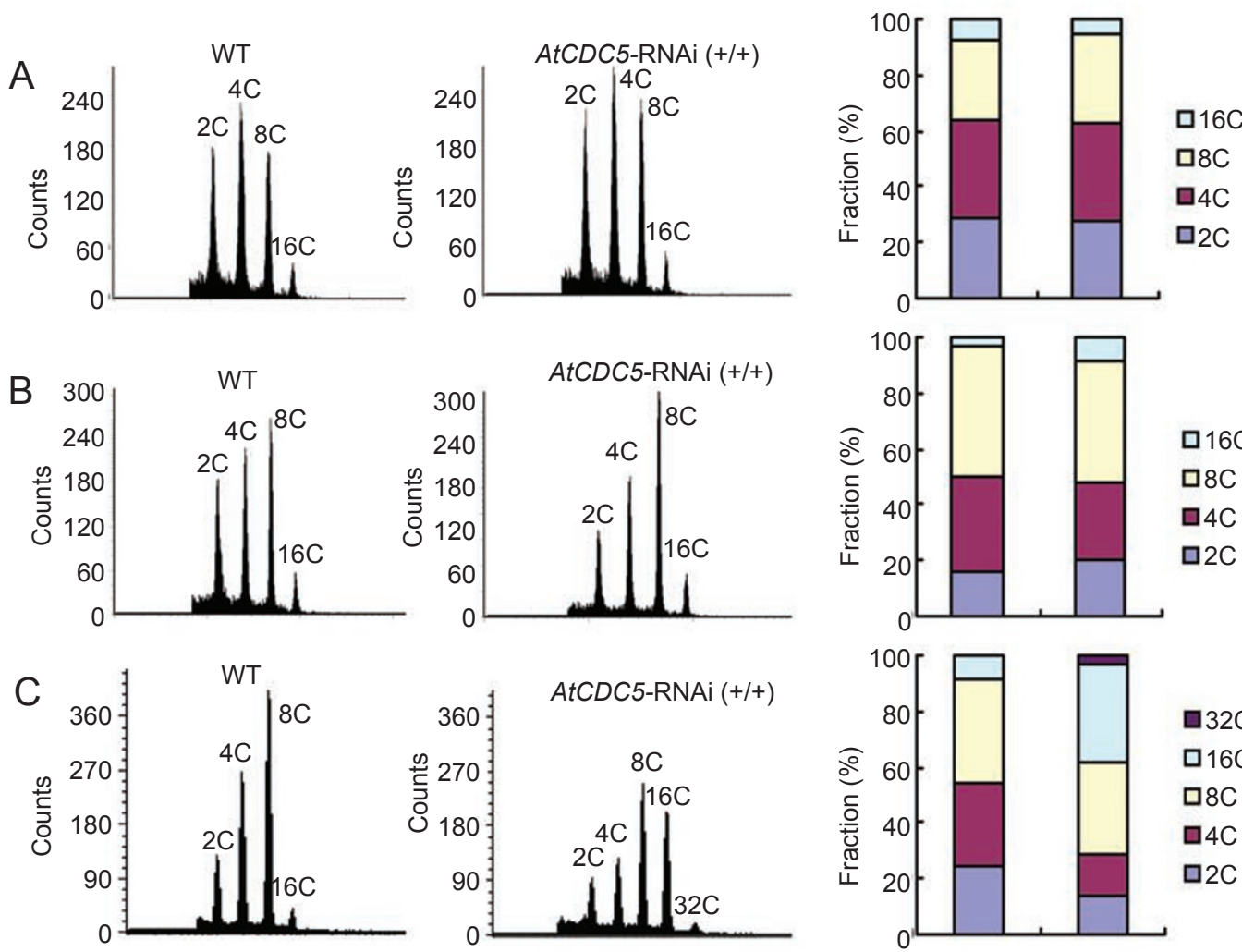

ㄴ32C

ㅁ16C

ㅁㄷ

ㄴㄷ

므

D
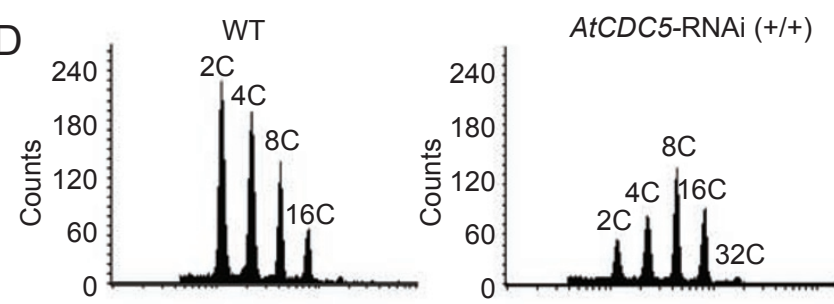

E

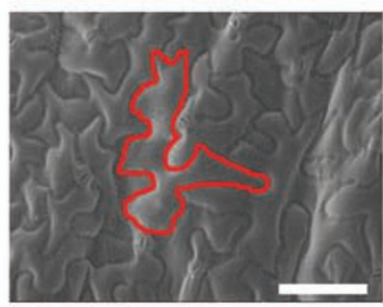

WT

F

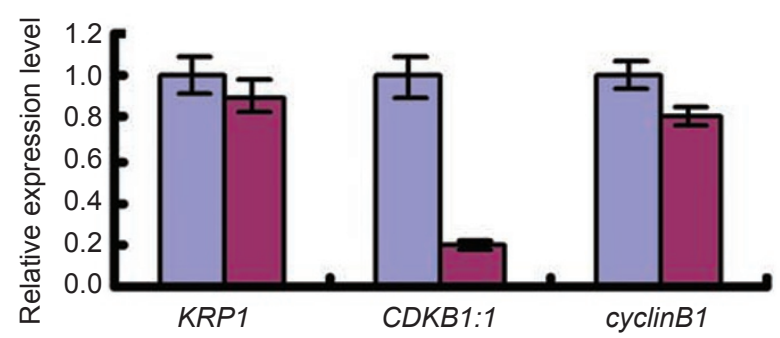

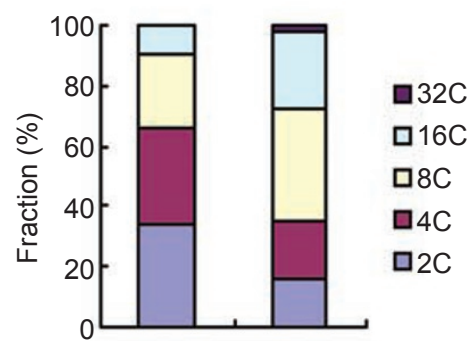

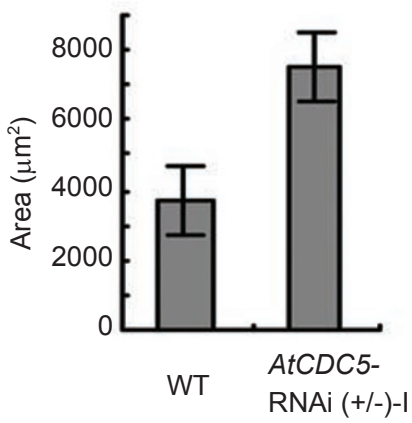



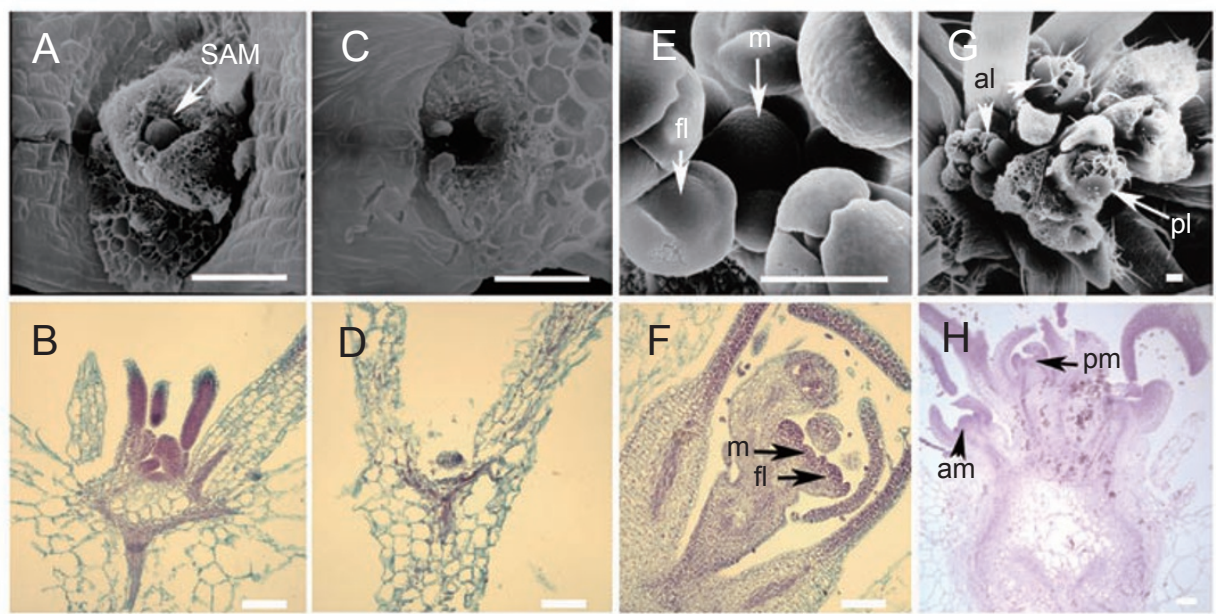

Figure 6 SEM and histological analysis of AtCDC5-RNAi (+/+) and (+/-)-I shoot apices. (A) Shoot apex of a 10-day-old WT seedling. (B) Section of the shoot apex of a 10-day-old WT seedling. (C) Shoot apex of a 10-day-old AtCDC5-RNAi (+/+) seedling. (D) Section of the shoot apex of a 10-day-old AtCDC5-RNAi (+/+) plant. The SAM is absent. (E) Inflorescence meristem (m) of a 35day-old WT plant. Floral meristems (fl) are initiated in a spiral arrangement. (F) Section of the shoot apex of a 30-day-old WT plant. (G) Shoot apices of a 35-day-old AtCDC5-RNAi (+/-)-I plant. The primary meristem leaf primordium (pl) and axillary meristem leaf primordium (al) are indicated by arrows. (H) Section of the shoot apex of a 35-day-old AtCDC5-RNAi (+/-)-I plant. The primary meristem $(\mathrm{pm})$ and axillary meristem $(\mathrm{am})$ are indicated by arrows. Bars: $(\mathbf{A}-\mathbf{D})=100 \mu \mathrm{m} ;(\mathbf{E}-\mathbf{H})=50 \mu \mathrm{m}$.

yeast and animals [21, 22], we needed to clarify whether cells from AtCDC5-RNAi plants display defects during the G2/M phase transition. Such defects can include being arrested at the $\mathrm{G} 2$ phase $[21,23,42]$ or entering the endocycle $[4,7]$. To address this problem, we used flow cytometry to measure the DNA content of cells in AtCDC5-RNAi (+/+) plants. At 7 days after sowing (DAS), nuclei from both wild type and AtCDC5-RNAi (+/+) seedlings displayed four main peaks that correspond to ploidy forms of $2 \mathrm{C}, 4 \mathrm{C}, 8 \mathrm{C}$ and $16 \mathrm{C}$. The ploidy level distribution of these plants was similar (Figure 5A). At 8 DAS, AtCDC5-RNAi (+/+) plants had an increased proportion of $8 \mathrm{C}$ cells as well as other polyploidy cells, but a decreased proportion of $4 \mathrm{C}$ cells and $2 \mathrm{C}$ cells (Figure 5B), suggesting that the mitotic cell cycle was suppressed. At $10 \mathrm{DAS}$, the proportion of $16 \mathrm{C}$ cells was largely increased in the AtCDC5-RNAi (+/+) plants and $32 \mathrm{C}$ cells emerged, whereas, in contrast, the proportion of $4 \mathrm{C}$ and $2 \mathrm{C}$ cells was further decreased (Figure 5C). This suggests that more cells escaped from the mitotic cell cycle and endoreduplication was triggered. At 11 DAS, the ploidy level distribution of the AtCDC5-RNAi (+/+) seedlings was similar to that of the 10 DAS plants (Figure 5D), suggesting that the ploidy level reached a steady state. Given that endoreduplication is always accompanied by cell enlargement [7], we examined the pavement epidermal cells of the fifth leaves in 35-day-old wild type and AtCDC5-RNAi $(+/-)-$ I plants to see whether endoreduplication is indeed increased in AtCDC5-RNAi plants. The results showed that the cells of the AtCDC5-RNAi (+/-)-I plants are larger than those of the wide type (Figure 5E). Therefore, these results suggest that the $\mathrm{G} 2 / \mathrm{M}$ phase transition is blocked in AtCDC5-RNAi plants, and that the defective cells escape mitosis and enter the endocycle.

To further clarify the regulation mechanism for the $\mathrm{G} 2 / \mathrm{M}$ phase transition, we examined the expression of $C D K B 1 ; 1$ and $K R P 1$, two genes that are important during the $\mathrm{G} 2 / \mathrm{M}$ phase transition [3, 4]. We also examined the expression of cyclinB1 in AtCDC5-RNAi (+/+) plants. Quantitative RT-PCR analysis showed that $C D K B 1 ; 1$ expression was severely reduced in the $A t C D C 5$ - RNAi $(+/+)$ plants, while both cyclinB1 and $K R P 1$ were slightly reduced (Figure $5 \mathrm{~F}$ ). This result suggests that the downregulation of $C D K B 1 ; 1$ might be the main cause for the defects in the G2/M phase transition.

\section{Severe AtCDC5-RNAi plants have impaired SAM func- tion}

To better understand the phenotype at the shoot apex, we examined SAMs of the AtCDC5-RNAi (+/+) and AtCDC5RNAi (+/-)-I plants by scanning electron microscope and histological analysis. At 10 DAS, wild-type seedlings possessed a hemisphere-shaped SAM (Figure 6A), but in AtCDC5-RNAi (+/+) seedlings a cavity was observed where a SAM should be present (Figure 6C). Histological 
analysis found no SAM structure (Figure 6D compared with WT in Figure 6B). In the 35-day-old wild-type plants that bolted (data not shown), the primary SAMs were transformed into inflorescence meristems and flower primordia were observed (Figure 6E). However, the AtCDC5-RNAi $(+/-)$-I plants that were at the same developmental stage did not bolt, and no inflorescence meristems and flower primordia were observed (Figure 6G). Instead, the primary SAMs of the AtCDC5-RNAi (+/-)-I plants were tightly covered by leaf primordia, and clustered leaf primordia were observed between rosette leaves (Figure 6G). This suggests that the development of the primary SAMs was disturbed. Histological analysis confirmed that while inflorescence meristems had been produced in the wild-type plants as early as 30 DAS (Figure 6F), no inflorescence meristems were found in the AtCDC5-RNAi (+/-)-I plants even at 35 DAS (Figure $6 \mathrm{H}$ ). This result suggests that the function rather than the establishment of SAMs was impaired. In addition, $A t C D C 5$-RNAi (+/-)-I plants developed some ax- illary meristems at this stage (Figure $6 \mathrm{H}$ ), implying that the impaired SAM development led to the loss of apical dominance. At approximately $60 \mathrm{DAS}$, these axillary meristems, but not the primary SAMs, developed into inflorescences (Figure 3E). These results, together with the dosage effect of $A t C D C 5$ on the phenotype of AtCDC5-RNAi plants, suggest that $A t C D C 5$ is essential for SAM function.

\section{Both the WUS-CLV and STM pathways are impaired in AtCDC5-RNAi plants}

Since no SAM was found in AtCDC5-RNAi (+/+) plants (Figure 6C) and SAMs with defective function were found in AtCDC5-RNAi (+/-)-I plants, it is possible that these plants have defects in the establishment and/or maintenance of SAM structures. To test this, we examined whether the three main component genes of the WUS-CLV signaling pathway, $C L V 3$, WUS and $C L V 1$, were affected by AtCDC5 deficiency. We crossed AtCDC5-RNAi plants with CLV3:: $G U S$ plants to examine the expression of $C L V 3$ in the $\mathrm{F} 2$
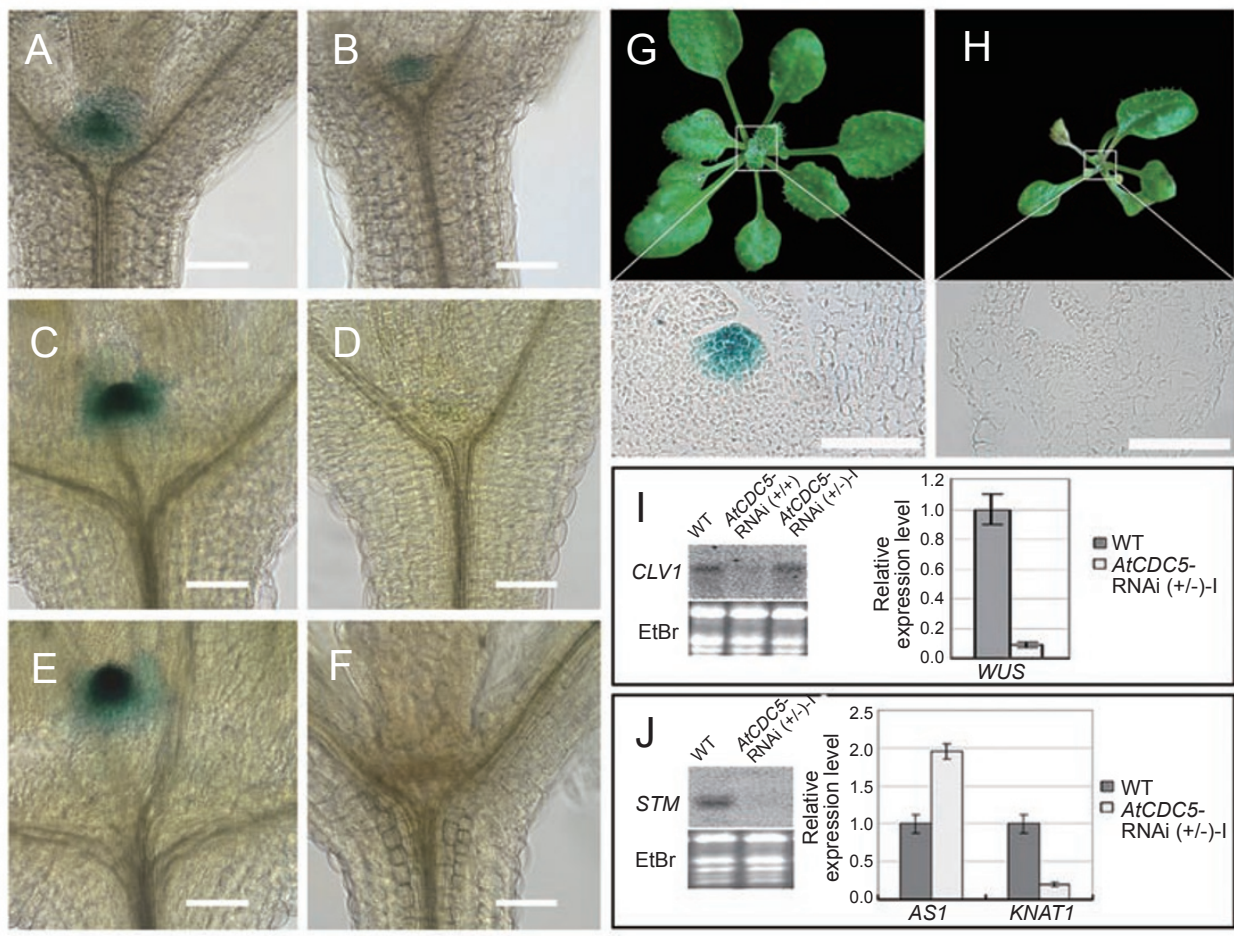
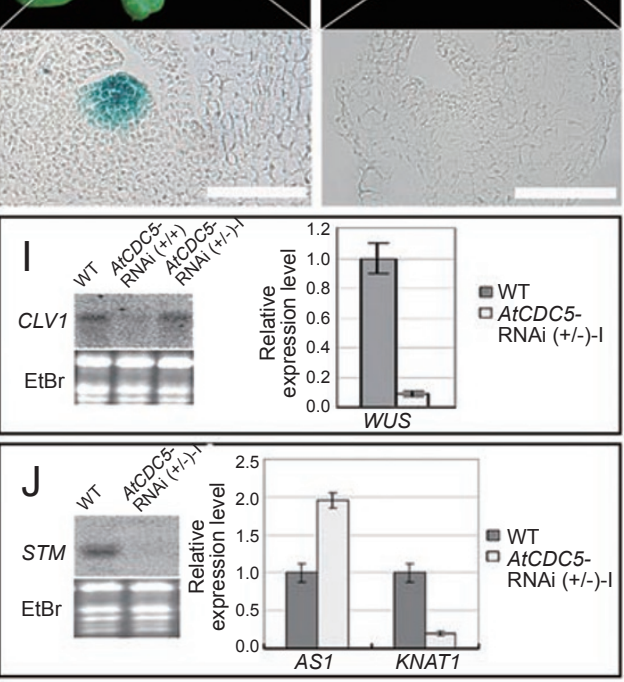

Figure 7 Expression of meristem development genes in AtCDC5-RNAi lines. (A, C and E) GUS-stained CLV3::GUS seedlings at 6 DAS, 8 DAS and 10 DAS, respectively. (B, D and F) GUS-stained CLV3:-GUS/AtCDC5-RNAi (+/+) plants at 6 DAS, 8 DAS and 10 DAS, respectively. (G and $\mathbf{H}) C L V 3:: G U S$ and $C L V 3: \because G U S / A t C D C 5-R N A i(+/-)-$ I plants at 25 DAS. (I) Northern blot analysis showing CLV1 expression. CLV1 expression was significantly reduced in AtCDC5-RNAi (+/+) plants but not in AtCDC5-RNAi (+/-)-I plants. Real-time qRT-PCR showed that WUS was also suppressed in AtCDC5-RNAi (+/-)-I plants. (J) Expression analysis of STM, AS1 and KNAT1 in WT and AtCDC5-RNAi (+/-)-I plants. Equal loading of the gel was confirmed by EtBr staining (bottom panel). The level of WUS, AS1 and KNAT1 mRNA was normalized to that of Ubiqutin-10 mRNA and the relative mRNA level was calculated in reference to the WT level. Experiments were repeated three times and SD is shown. Bars $=50 \mu \mathrm{m}$. 


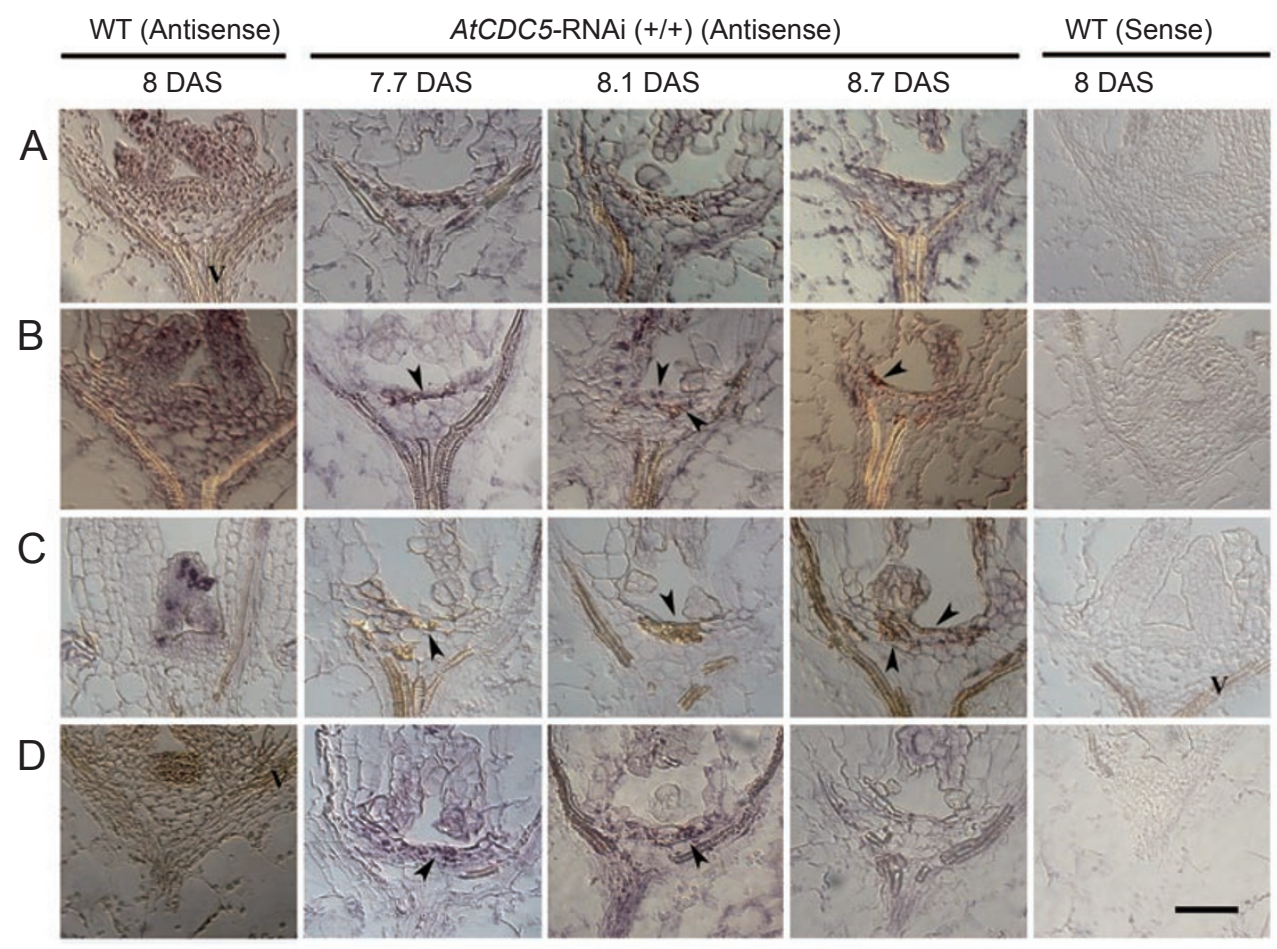

Figure 8 Expression patterns of AtCDC5, cyclinB1, Histone4 and STM in AtCDC5-RNAi (+/+) plants. The expression patterns of AtCDC5, cyclinB1, Histone 4 and STM in the AtCDC5-RNAi (+/+) plants were determined by in situ hybridization. AtCDC5-RNAi $(+/+)$ plants at 7.7 DAS $(7$ DAS $+16.8 \mathrm{~h}), 8.1$ DAS $(8 \mathrm{DAS}+2.4 \mathrm{~h}), 8.7 \mathrm{DAS}(8 \mathrm{DAS}+16.8 \mathrm{~h})$ and wild-type plants at $8 \mathrm{DAS}$ were used in this assay. Wild-type plants that were hybridized with antisense probes and sense probes were used as positive and negative controls, respectively. (A) AtCDC5. V: vascular tissue. (B) cyclinB1. Arrowheads indicate cells expressing cyclineB1. (C) Histone4. Arrowheads indicate cells expressing Histone4. (D) $S T M$. Arrowheads indicate cells expressing STM. Bars $=50 \mu \mathrm{m}$.

generation [41]. The results showed that CLV3::GUS was constitutively expressed in the wild type (Figure 7A, 7C and 7E). However, in AtCDC5-RNAi (+/+) plants CLV3 expression was detected at 6 DAS (Figure 7B), but was significantly downregulated at 8 DAS (Figure 7D), and was undetectable at 10 DAS (Figure 7F), suggesting that the SAM was established at an early stage but was not maintained. $C L V 3$ was also suppressed in AtCDC5-RNAi $(+/-)-$ I plants (Figure $7 \mathrm{G}$ and $7 \mathrm{H})$. Northern blot analysis showed that the expression of $C L V 1$ was undetectable in AtCDC5-RNAi (+/+) plants but not affected in AtCDC5RNAi (+/-)-I plants (Figure 7I), suggesting that there is no SAM in AtCDC5-RNAi (+/+) plants. Because we could not detect the expression of WUS in either wild type or AtCDC5-RNAi plants by northern blot analysis, we used real-time qRT-PCR. Our results showed that WUS was significantly reduced in AtCDC5-RNAi (+/-)-I plants (Figure 7I) and could not be detected in AtCDC5-RNAi (+/+) plants (data not shown). Together, these data suggest that the WUS-CLV signaling pathway becomes suppressed in $A t C D C 5$-RNAi plants, and defective AtCDC5 function interferes with the maintenance of SAM, rather than its establishment.

Since the STM signaling pathway is independent of the WUS-CLV pathway, we also examined the three main components of this pathway, i.e., STM, AS1 and KNAT1. Northern blot result showed that the expression of $S T M$ was suppressed in AtCDC5-RNAi(+/-)-I plants (Figure 7J). Quantitative RT-PCR analysis showed that the expression of $A S 1$ was upregulated, while $K N A T 1$ was downregulated (Figure $7 \mathrm{~J}$ ), suggesting that the STM signaling pathway was indeed affected in AtCDC5-RNAi plants.

STM expression is reduced in the shoot apex region of AtCDC5-RNAi plants

We wanted to clarify whether the SAM defects in $A t C D C 5$-RNAi plants result from an impairment in the G2/M phase transition and a subsequent decrease in cell division, or from downregulation of both WUS and STM by $A t C D C 5$. To do this, we examined the expression of two cell cycle marker genes, cyclinB1 and Histone4, and that of $S T M$ in the shoot apex region of $A t C D C 5$-RNAi plants. 
AtCDC5 was highly expressed in the SAM and leaf primordia in the wild-type plants, but was restricted to some cells in the shoot apex of the AtCDC5-RNAi plants at 7.7 DAS. The expression was further attenuated at 8.1 and 8.7 DAS (Figure 8A). These data suggest that AtCDC5 expression is indeed silenced in these plants.

In wild-type plants, $\operatorname{cyclin} B 1$, specifically expressed in the $\mathrm{G} 2$ or $\mathrm{M}$ phase $[43,44]$, was not detected in the top two cell layers of the SAM (Figure 8B). However, cyclinB1 was found to be abundant in the apical cells of the 7.7 DAS AtCDC5-RNAi plants (Figure 8B, 7.7 DAS, arrowhead). At 8.1 DAS, fewer cells were found to express $\operatorname{cyclinB1}$; these were mainly restricted to the peripheral zone of the shoot apex (Figure 8B, 8.1 DAS, arrowheads). At 8.7 DAS, cyclinB1 expression could still be detected in some cells in the peripheral zone of the shoot apex (Figure 8B, 8.7 DAS, arrowhead). Histone4, which is S-phase-specific [45], was highly expressed in some leaf primordia cells in the wild-type plants, but could not be detected in the central zone of the SAM (Figure 8C). In the AtCDC5-RNAi plants, Histone 4 could be detected in some cells localized in the central zone of the shoot apex at 7.7 DAS, and in more central zone cells at 8.1 DAS (Figure 8C). At 8.7 DAS, Histone 4 expression had declined, and was mainly detected in the topside cell layer and peripheral zone of the shoot apex (Figure 8C, 8.7 DAS, arrowheads). The expression patterns of these two cell cycle marker genes in AtCDC5RNAi plants suggest that the cell cycle is disturbed in the shoot apex region of AtCDC5-RNAi (+/+) plants.

$S T M$ transcripts were detected in shoot apex cells of the 7.7-day-old and 8.1-day-old AtCDC5-RNAi (+/+) plants. However, $S T M$ expression was reduced and restricted to one or two cell layers compared with the wild-type plants (Figure 8D), suggesting that the ability of STM to maintain SAM cells in an undifferentiated state was diminished [12]. At 8.7 DAS, the STM transcript could not be detected (Figure 8D, 8.7 DAS), implying that STM regulation is completely lost in the shoot apex cells of AtCDC5-RNAi $(+/+)$ plants.

\section{STM overexpression can partially rescue defective AtCDC5 function}

To test the hypothesis mentioned above, we overexpressed STM in AtCDC5-RNAi plants and obtained five transformants - two were sterile and the other three had inflorescences that terminated prematurely (data not shown). The T3 progeny of the three fertile lines were selected for an $A t C D C 5$-RNAi (+/+) background and named $35 S:$ :
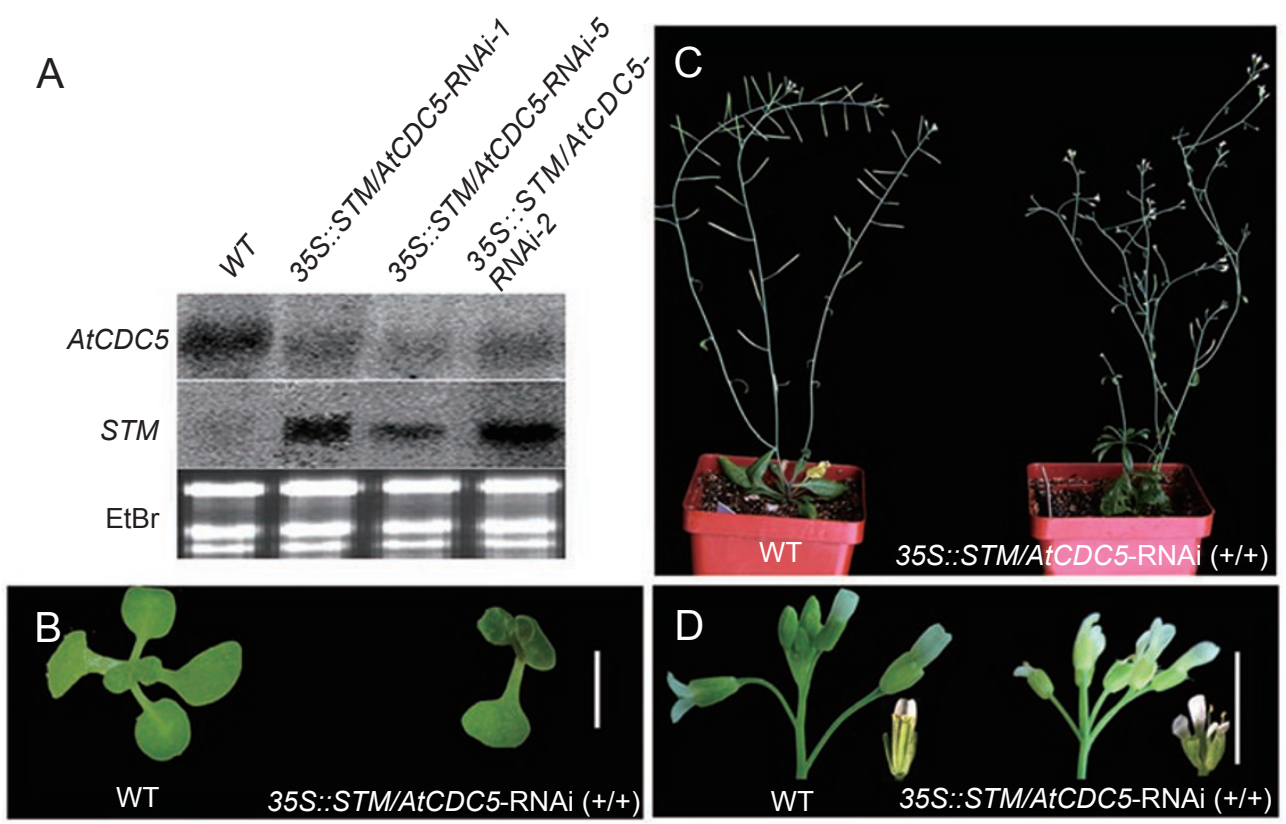

Figure 9 Partial rescue of the AtCDC5-RNAi (+/+) phenotype by $35 S:: S T M$. (A) RNA gel blot analysis of AtCDC5 and STM in 35S:: STM/AtCDC5-RNAi (+/+) plants. Three independent lines were used in this assay. (B) Phenotypes of 13-day-old WT and 35S::STM/ AtCDC5-RNAi (+/+) seedlings. (C) Phenotypes of 50-day-old WT and 35S::STM/AtCDC5-RNAi (+/+) plants. (D) Inflorescences of WT and 35S::STM/AtCDC5-RNAi (+/+) plants. The 35S::STM/AtCDC5-RNAi (+/+) inflorescences terminated prematurely and their flowers lacked carpels. Bars: (B and D) $0.5 \mathrm{~cm}$. 
STM/AtCDC5-RNAi (+/+)-1, 2 and 5. In these three lines, AtCDC5 expression was silenced and STM was overexpressed (Figure 9A).

Unlike the AtCDC5-RNAi (+/+) plants, the 35S::STM/ AtCDC5-RNAi (+/+) seedlings did not show any lesions. Leaves were formed, although at a slower rate, and at 13 DAS, when the wild-type counterpart had four leaves, the 35S::STM/AtCDC5-RNAi (+/+) plant generated one true leaf (Figure 9B). Throughout development, rosette leaves and shoots randomly emerged (Figure 9C), and no lesion-like pale spots were observed. Inflorescences of 35S::STM/AtCDC5-RNAi (+/+) plants showed a "stop and go" growth pattern, i.e. inflorescences prematurely terminated and, at the same time, new inflorescences emerged from the axils of cauline leaves (Figure 9C), resembling wus mutants [11]. Additionally, most $35 S:$ : STM/AtCDC5-RNAi (+/+) flowers were missing carpels and two or more stamens (Figure 9D). Although similar to wus plants, their phenotype was weaker, and they were partially fertile. These results support our hypothesis that the SAM defects of the RNAi lines are partially mediated through the downregulation of STM.

These data, together with the expression pattern of $C L V 3$, suggest that the defects of the AtCDC5-RNAi plants in maintaining the SAM might be caused by the reduced expression of STM or WUS, which in turn results in the complete consumption of the SAM cells.

\section{Discussion}

To characterize the function of $A t C D C 5$, we examined plants that had reduced activity of this gene. Homozygotic lines of a T-DNA insertion mutant atcdc5-1 were not obtained, and analysis of seeds developing inside the heterozygote individuals showed that individuals that are homozygous for the insertion halted at the zygote stage. Therefore, the homozygous AtCDC5 loss-of-function mutant is embryonic lethal (Figure 1). The RNAi lines with partially reduced AtCDC5 activity exhibited pleiotropic defects, indicating continuous and widespread functions of the gene (Figure 3). This is supported by the expression pattern of $A t C D C 5$, which was expressed throughout embryogenesis and in most post-embryonic tissues, such as inflorescence meristems, SAMs, and flower and leaf primordia (Figures 2 and 8). Publicly available AtCDC5 expression data from various microarray analyses, which we surveyed using the Genevestigator database [46], agree with our in situ hybridization results.

In this study, we found that downregulation of $A t C D C 5$ reduced, rather than increased, the proportion of $\mathrm{G} 2 / \mathrm{M}$ phase cells, and increased that of the polyploidy cells (Figure 5). This phenotype is different from that seen in cultured cells of yeast and mammals, in which CDC5 defects result in cell cycle arrest at the G2 phase [21, 23]. This difference is possibly associated with the mechanism of organ size control that exists in multicellular organisms [47]. For instance, in Drosophila, inactivation of the Cdc2 kinase blocked the G2/M phase transition and increased endoreduplication. Therefore, because the cell size increases, the final size and shape of the pupal wing was not affected [48]. In Arabidopsis, it was also reported that cells often compensate for a shortage in number of cells by increasing cell size during leaf development [49]. Our data showed that the AtCDC5-RNAi plants had both reduced expression of $C D K B 1 ; 1$ and increased cell size (Figure 5), supporting this hypothesis. Thus, we conclude that, instead of being arrested at the $\mathrm{G} 2$ phase, endoreduplication was used by the $A t C D C 5$-defective cells as an efficient way to maintain the final size of organs [7].

The most striking developmental phenotype of the AtCDC5-RNAi plants was the loss of SAM (Figure 6). It is well known that mutants with affected cell cycles also exhibit meristem termination phenotypes (for instance, double mutants of ribonucleotide reductase (tso2-1 rnr2a1) that have defects in S-phase progression [45]). Cell cycle progression is vital for the maintenance of SAM and failure in cell cycle progression will generally destroy the balance in SAM cell numbers and result in SAM termination. In this study, we found that $A t C D C 5$-RNAi plants had comparable $C L V 3$ expression with wild-type plants at 6 DAS, but had much lower expression at $8 \mathrm{DAS}$, and even no expression at 10 DAS (Figure 7A-F). This suggests that stem cells exist before 6 DAS but they are lost after 8 DAS. Since both the G2/M phase transition and SAM maintenance pathways were suppressed in AtCDC5-RNAi plants, it is difficult to decide which one corresponds to the loss of stem cells. However, the fact that cyclinB1 and Histone 4 were expressed in the shoot apical cells of the AtCDC5RNAi plants at 8.1 DAS and 8.7 DAS suggests that these cells can still enter mitosis at this time. This observation argues against the possibility that the loss of stem cells was caused by the failure of the cell cycle. From the evidence that the reduction of STM was tightly correlated with the loss of stem cells (Figure 8D), together with the fact that the STM and WUS-CLV pathways are both required for the maintenance of the SAM [50], we propose that these two pathways are suppressed in the AtCDC5-RNAi plants. The suppression consequently causes the loss of stem cells, and then the absence of stem cells eventually contributes to the loss of SAM in the AtCDC5-RNAi plants.

Taking into consideration that $A t C D C 5$ was expressed at the beginning of embryogenesis, and that WUS and STM were downregulated in $A t C D C 5$-RNAi plants, a straightforward interpretation is that AtCDC5 is involved in regulating 
the expression of these two genes. This hypothesis is further supported by our data, which show that overexpression of STM can partially rescue the phenotype caused by defective AtCDC5 function (Figure 9). However, many questions remain to be answered. For example, are WUS and STM the direct targets of AtCDC5? Does AtCDC5 function as a transcription factor or as an mRNA splicing factor? All these issues need to be elucidated in the future.

In conclusion, our data in this study demonstrate that AtCDC5 is a cell cycle regulator that is important for the G2/M phase transition. It also plays an essential role in SAM maintenance, possibly through regulating $W U S$ and STM expression.

\section{Acknowledgments}

The authors thank Dr Liying Du (Peking University, China) for technical help on the flow cytometric analysis. The authors also thank Dr Zhongchi Liu (University of Maryland, USA), Dr Chun-Ming Liu (Institute of Botany CAS, China), Dr Terry Matthew (University of Southampton, UK), Professor Daochun Kong (Peking University, China) and Dr Naomi Nakayama (Yale University, USA) for critical comments and valuable discussion. This work was supported by the National Natural Science Foundation of China (GN 30625002 to L-J Qu).

\section{References}

1 Brodsky VY, Uryvaeva IV. Cell polyploidy: its relation to tissue growth and function. Int Rev Cytol 1977; 50:275-332.

2 D'Amato F. Endopolyploidy as a factor in plant tissue development. Caryologia 1964; 17:41-52.

3 Boudolf V, Barrôco R, Engler Jde A, et al. B1-type cyclin-dependent kinases are essential for the formation of stomatal complexes in Arabidopsis thaliana. Plant Cell 2004; 16:945-955.

4 Boudolf V, Vlieghe K, Beemster GT, et al. The plant-specific cyclin-dependent kinase CDKB1;1 and transcription factor E2Fa$\mathrm{DPa}$ control the balance of mitotically dividing and endoreduplicating cells in Arabidopsis. Plant Cell 2004; 16:2683-2692.

5 Weinl C, Marquardt S, Kuijt SJ, et al. Novel functions of plant cyclin-dependent kinase inhibitors, ICK1/KRP1, can act noncell-autonomously and inhibit entry into mitosis. Plant Cell 2005; 17:1704-1722.

6 Schnittger A, Weinl C, Bouyer D, Schobinger U, Hülskamp M. Misexpression of the cyclin-dependent kinase inhibitor ICK1/ KRP1 in single-celled Arabidopsis trichomes reduces endoreduplication and cell size and induces cell death. Plant Cell 2003; 15:303-315.

7 Sugimoto-Shirasu K, Roberts K. "Big it up": endoreduplication and cell-size control in plants. Curr Opin Plant Biol 2003; 6:544553.

8 Barton MK, Poethig RS. Formation of the shoot apical meristem in Arabidopsis thaliana: an analysis of development in the wild type and in the shoot meristemless mutant. Development 1993; 119:823-831.
9 Clark SE, Jacobsen SE, Levin JZ, Meyerowitz EM. The CLAVATA and SHOOT MERISTEMLESS loci competitively regulate meristem activity in Arabidopsis. Development 1996; 122:1567-1575

10 Endrizzi K, Moussian B, Haecker A, Levin JZ, Laux T. The SHOOT MERISTEMLESS gene is required for maintenance of undifferentiated cells in Arabidopsis shoot and floral meristems and acts at a different regulatory level than the meristem genes WUSCHEL and ZWILLE. Plant J 1996; 10:967-979.

11 Laux T, Mayer KFX, Berger J, Jürgens G. The WUSCHEL gene is required for shoot and floral meristem integrity in Arabidopsis. Development 1996; 122:87-96.

12 Long J, Moan E, Medford J, Barton M. A member of the KNOTTED class of homeodomain proteins encoded by the STM gene of Arabidopsis. Nature 1996; 379:66-69.

13 Schoof H, Lenhard M, Haecker A, Mayer KFX, Jurgens G, Laux T. The stem cell population of Arabidopsis shoot meristems is maintained by a regulatory loop between the CLAVATA and WUSCHEL genes. Cell 2000; 100:635-644.

14 Trotochaud A, Jeong S, Clark S. CLAVATA3, a multimeric ligand for the CLAVATA1 receptor-kinase. Science 2000; 289:613617.

15 Byrne M, Barley R, Curtis M, et al. Asymmetric leaves 1 mediates leaf patterning and stem cell function in Arabidopsis. Nature 2000; 408:967-971.

16 Iwakawa H, Ueno Y, Semiarti E, et al. The ASYMMETRIC LEAVES2 gene of Arabidopsis thaliana, required for formation of a symmetric flat leaf lamina, encodes a member of a novel family of proteins characterized by cysteine repeats and a leucine zipper. Plant Cell Physiol 2002; 43:467-478.

17 Ori N, Eshed Y, Chuck G, Bowman JL, Hake S. Mechanisms that control knox gene expression in the Arabidopsis shoot. Development 2000; 127:5523-5532.

18 Semiarti E, Ueno Y, Tsukaya H, Iwakawa H, Machida C, Machida Y. The asymmetric leaves2 gene of Arabidopsis thaliana regulates formation of a symmetric lamina, establishment of venation and repression of meristem-related homeobox genes in leaves. Development 2001; 128:1771-1783.

19 de Jager SM, Maughan S, Dewitte W, Scofield S, Murray JA. The developmental context of cell-cycle control in plants. Semin Cell Dev Biol 2005; 16:385-396.

20 Ohi R, Feoktistova A, McCann S, et al. Myb-related Schizosaccharomyces pombe cdc5p is structurally and functionally conserved in eukaryotes. Mol Cell Biol 1998; 18:4097-4108.

21 Ohi R, McCollum D, Hirani B, et al. The Schizosaccharomyces pombe cdc5+ gene encodes an essential protein with homology to c-Myb. EMBO J 1994; 13:471-483.

22 Bernstein HS, Coughlin SR. Pombe Cdc5-related protein. A putative human transcription factor implicated in mitogen-activated signaling. J Biol Chem 1997; 272:5833-5837.

23 Bernstein HS, Coughlin SR. A mammalian homolog of fission yeast $\mathrm{Cdc} 5$ regulates $\mathrm{G} 2$ progression and mitotic entry. J Biol Chem 1998; 273:4666-4671.

24 Hirayama T, Shinozaki K. A cdc5+ homolog of a higher plant, Arabidopsis thaliana. Proc Natl Acad Sci USA 1996; 93:1337113376.

25 Lei X, Shen X, Xu X, Bernstein H. Human Cdc5, a regulator of mitotic entry, can act as a site-specific DNA binding protein. J Cell Sci 2000; 113:4523-4531. 
26 Ajuh P, Kuster B, Panov K, Zomerdijk JC, Mann M, Lamond AI. Functional analysis of the human CDC5L complex and identification of its components by mass spectrometry. EMBO J 2000; 19:6569-6581.

27 Burns CG, Ohi R, Krainer AR, Gould KL. Evidence that Mybrelated CDC5 proteins are required for pre-mRNA splicing. Proc Natl Acad Sci USA 1999; 96:13789-13794.

28 Liu L, Graub R, Hlaing M, et al. Distinct domains of human CDC5 direct its nuclear import and association with the spliceosome. Cell Biochem Biophys 2003; 39:119-132.

29 McDonald WH, Ohi R, Smelkova N, Frendewey D, Gould KL. Myb-related fission yeast cdc $5 p$ is a component of a $40 \mathrm{~S}$ snRNPcontaining complex and is essential for pre-mRNA splicing. Mol Cell Biol 1999; 19:5352-5362.

30 Tsai WY, Chow YT, Chen HR, et al. Ceflp is a component of the Prp19p-associated complex and essential for pre-mRNA splicing. J Biol Chem 1999; 274:9455-9462.

31 Burns CG, Ohi R, Mehta S, et al. Removal of a single alphatubulin gene intron suppresses cell cycle arrest phenotypes of splicing factor mutations in Saccharomyces cerevisiae. Mol Cell Biol 2002; 22:801-815.

32 Dahan O, Kupiec M. Mutations in genes of Saccharomyces cerevisiae encoding pre-mRNA splicing factors cause cell cycle arrest through activation of the spindle checkpoint. Nucleic Acids Res 2002; 30:4361-4370.

33 Lin Z, Yin K, Wang X, et al. Virus induced gene silencing of AtCDC5 results in accelerated cell death in Arabidopsis leaves. Plant Physiol Biochem 2007; 45:87-94.

34 Chuang CF, Meyerowitz EM. Specific and heritable genetic interference by double-stranded RNA in Arabidopsis thaliana. Proc Natl Acad Sci USA 2000; 97:4985-4990.

35 Clough SJ, Bent AF. Floral dip: a simplified method for Agrobacterium-mediated transformation of Arabidopsis thaliana. Plant J 1998; 16:735-743.

36 Qin GJ, Gu HY, Zhao YD, et al. An indole-3-acetic acid carboxyl methyltransferase regulates Arabidopsis leaf development. Plant Cell 2005; 17:2693-2704.

37 Qu LJ, Chen J, Liu MH, et al. Molecular cloning and functional analysis of a novel type of Bowman-Birk inhibitor gene family in rice. Plant Physiol 2003; 133:560-570.

38 Guo L, Wang ZY, Lin H, et al. Expression and functional analysis of the rice plasma-membrane intrinsic protein gene family. Cell Res 2006; 16:277-286.

39 Galbraith DW, Harkins KR, Maddox JM, Ayres NM, Sharma DP, Firoozabady E. Rapid flow cytometric analysis of the cell cycle in intact plant tissues. Science 1983; 220:1049-1051.

40 Liu CM, Meinke DW. The titan mutants of Arabidopsis are disrupted in mitosis and cell cycle control during seed development. Plant J 1998; 16:21-31.

41 Brand U, Grunewald M, Hobe M, Simon R. Regulation of CLV3 expression by two homeobox genes in Arabidopsis. Plant Physiol 2002; 129:565-575.

42 Porceddu A, Stals H, Reichheldt J, et al. A plant-specific cyclindependent kinase is involved in the control of $\mathrm{G}(2) / \mathrm{M}$ progression in plants. J Biol Chem 2001; 276:36354-36360.

43 Ferreira PC, Hemerly AS, Engler JD, van Montagu M, Engler G, Inze D. Developmental expression of the Arabidopsis cyclin gene cyc1At. Plant Cell 1994; 6:1763-1774.

44 Hemerly A, Bergounioux C, Vanmontagu M, Inze D, Ferreira P. Genes regulating the plant cell cycle isolation of a mitotic-like cyclin from Arabidopsis thaliana. Proc Natl Acad Sci USA 1992; 89:3295-3299.

45 Wang CX, Liu ZC. Arabidopsis ribonucleotide reductases are critical for cell cycle progression, DNA damage repair, and plant development. Plant Cell 2006; 18:350-365.

46 Zimmermann P, Hirsch-Hoffmann M, Hennig L, Gruissem W. GENEVESTIGATOR. Arabidopsis microarray database and analysis toolbox. Plant Physiol 2004; 136:2621-2632.

47 Potter CJ, Xu T. Mechanisms of size control. Curr Opin Genet Dev 2001; 11:279-286.

48 Weigmann K, Cohen SM, Lehner CF. Cell cycle progression, growth and patterning in imaginal discs despite inhibition of cell division after inactivation of Drosophila Cdc2 kinase. Development 1997; 124:3555-3563.

49 Tsukaya H. Organ shape and size: a lesson from studies of leaf morphogenesis. Curr Opin Plant Biol 2003; 6:57-62.

50 Gross-Hardt R, Laux T. Stem cell regulation in the shoot meristem. J Cell Sci 2003; 116:1659-1666.

(Supplementary information is linked to the online version of the paper on the Cell Research website.) 